http://www.jfas.info

\title{
THE EFFECT OF AQUEOUS EXTRACT OF CARAWAY SEED (CARUM CARVI) ON CHOLECYSTOKININ HORMONE IN MALE RAT
}

\author{
M. Pourahmadi ${ }^{1}$, H. K. Jahromi ${ }^{2, *}$ and Y. Rooeintan ${ }^{3}$
}

1Research Center for non. Communicable Diseases, Jahrom University of Medical Sciences, Jahrom, Iran

2Zoonoses Research center, Jahrom University of Medical Sciences, Jahrom, Iran 3Student Research Committee, Jahrom University of Medical Sciences, Jahrom, Iran

Published online: 15 June 2016

\begin{abstract}
Introduction: Today, obesity is considered as one of the problems of human society. Obesity is the underlying cause of chronic diseases such as cardiovascular disease, diabetes, and hyperlipidemia and hormone disruption. In addition to physiological problems, obesity leads to impaired psychosocial dimensions and reduced quality of life. Cholecystokinin is an anti-appetite peptidpe that plays a key role in the regulation of energy balance. Given the antioxidant and anti-appetite effects of caraway, the objective of this study is to investigate the impact of aqueous extract of caraway seed (carum carvi) on cholecystokinin hormone in male rat.

Method: In this experimental study, 32 adult female Wistar rats were divided into 4 groups of 8 including control, yardstick, and experiment recipient of caraway (at concentrations of 60 and $90 \mathrm{mg} / \mathrm{kg})$.
\end{abstract}

Author Correspondence, e-mail: hossein.kargarjahromi@yahoo.com

doi: http://dx.doi.org/10.4314/jfas.v8i2s.162 
Caraway was administered to the animals by gavage. In the fifty-seventh days after the start of the experiment, the animals were weighed, blood samples were taken from heart, and serum levels of cholecystokinin hormone and lipid parameters were measured. The results were analyzed using statistical ANOVA test and Duncan's test at significance level of $\mathrm{p} \unlhd 0.05$. Results: The mean concentration of cholecystokinin hormone in the group receiving caraway at concentrations of 60 and $90 \mathrm{mg} / \mathrm{kg}$ showed significant increase compared to the control group. The average concentration of triglycerides, total cholesterol, and LDL concentrations in the groups receiving caraway of 60 and $90 \mathrm{mg} / \mathrm{kg}$ showed a significant decrease compared to the control group. The average concentration of HDL in the group receiving caraway with a concentration of 60 and $90 \mathrm{mg} / \mathrm{kg}$ showed no significant difference with the control group.

Conclusion: caraway due to the antioxidant effects leads to increased cholecystokinin hormone secretion and reduced triglyceride, total cholesterol, and LDL in the rats.

Caraway is a medicinal plant used in Iranian traditional medicine as a treatment for overweight and obesity. Black cumin (caraway) is perennial herb of umbelliferae family with the scientific name carum carvi or Bunium persicus boiss (6). The results of purification and studying combinations of caraway show that the aqueous phase of this product has 19 monoterpenoids and a variety of its compounds: aromatic, flavonoids, and nucleoside glucoside. The main components of this essential oil extracted from caraway seeds, which are among the monoterpenes, have anti-inflammatory properties, and oral administration of them reduces the effects of intestinal inflammation in rats (7). This plant in traditional medicine has uses in antifouling of muscles, carminative, appetizer, mucus, increasing milk secretion, and in food industry is used as a flavoring (8). Antifungal (9), antimicrobial (10), antispasmodic (11), analgesic and anti-inflammatory (12) and the anticonvulsant (13) effects of compounds in caraway extract have been approved. It is reported that aqueous extract of caraway lowers blood lipids level (14) and weight loss effects in normal and diabetic rats have been demonstrated (15). Due to the effect of this plant on weight loss and that no study on the impact of caraway on cholecystokinin hormone, which as noted is called satiety peptide, this study will be conducted aimed at studying the impact of caraway on cholecystokinin hormone. 
keywords: aqueous extract; cholecystokinin hormone; caraway seed (carum carvi).

\section{INTRODUCTION}

Today, obesity is considered as one of the problems of human society. Obesity is the underlying cause of chronic diseases such as cardiovascular disease, diabetes, and hyperlipidemia and hormone disruption (1). In addition to physiological problems, obesity leads to impaired psychosocial dimensions and reduced quality of life (2). According to research, obesity has $19 \%$ prevalence in Iran that compared to low-income countries to middle-income countries can strongly indicate that Iran population is at increased risk of obesity (3). Due to the physical and psychological effects of obesity, experts are trying to reduce the spread of this scourge through various methods. Different mechanisms are involved in the physiology of obesity, overcoming each of which can be considered a treatment for obesity. Loss of appetite is of obesity treatments. Different hormones such as cholecystokinin, leptin, ghrelin, and so on are involved in determining the appetite. Cholecystokinin and leptin reduce appetite and ghrelin increases appetite. This study was conducted on the cholecystokinin hormone. Cholecystokinin is a 33-amino acid peptide that is produced through intestinal endocrine cells, different neurons in the gastrointestinal area, and central nervous system. This hormone can also act as a neuropeptide cholecystokinin acts via two receptors. CCK-B type receptors are present mainly in the brain tissue and CCK-A receptors, although largely concentrated in the digestive system, they are found in certain brain areas as well. Cholecystokinin does various functions in humans and animals including the ability to create a feeling of satiety and reduce food intake, prevention of gastric emptying, prevention of gastric acid secretion and stimulating intestinal peristalsis (4), thus, it is of hormones contributing to reducing obesity. Of synthetic drugs are approved, orlistat and sibutramine are for long-term use in the treatment of obesity and overweight, but besides high prices and having significant side effects, they have low efficacy in treating obesity, so other drugs and methods with fewer side effects and higher effectiveness are needed for the treatment of obesity and overweight (5). For this purpose, the use of medicinal plants can be an appropriate option. 


\section{METHOD}

For this study, 32 male Wistar rats with an average weight of 200-250, and 10 weeks of age were used. The mice were kept in 4-case cages, and a week after environmental adaptation and observing the darkness and light cycle including 12 hours darkness and 12 hours light, and environment dampness about 50 to 55, and feeding with standard food and pipeline water as needed, the intended rats were taken blood samples from and then were excluded from the study. The first group is the control group fed with standard food and water and gavage with distilled water was done on them.

The second group is the first experimental group, which in addition to feeding by standard supply of water and food, aqueous extract of caraway, with the daily amount of $60 \mathrm{mg}$ per $\mathrm{kg}$ based on each body weight in kilogram and dissolved in $1 \mathrm{ml}$ of distilled water, was given to them by gavage for 8 weeks (14). The third group is the experimental group 2 that in addition to feeding with standards food and water and aqueous extract of caraway, with the daily amount of $90 \mathrm{mg}$ per $\mathrm{kg}$ based on each body weight in kilogram and dissolved in $1 \mathrm{ml}$ of distilled water, was given to them by gavage for 8 weeks. After finishing the job, mice were weighed and then anesthetized with diethyl ether and blood samples were directly taken from the heart by the syringe $5 \mathrm{cc}$. Blood serum was collected by centrifugation (3000 rpm for 15 minutes), and until the time to send to the lab to determine the concentrations of the cholecystokinin hormone serum and serum levels of TC, TG, HDL, LDL, blood serum were kept in freezer at $-70 \circ \mathrm{C}$. The results of ANOVA statistical and Duncan's test were analyzed at the significant level of $\mathrm{p} \leq 0.05$.

\section{The preparation of aqueous extract of caraway}

One hundred grams of caraway seed powder was mixed with $200 \mathrm{ml}$ of distilled water and then using an electric mixer was stirred for three days. Then the obtained liquid mixture was separated by filtration and dried at $40^{\circ} \mathrm{C}$ and the dried sample was kept at a temperature of $-20^{\circ} \mathrm{C}$ away from dampness.

\section{Findings:}

Statistical studies and comparisons between the results of the changes in serum concentrations of cholecystokinin, TC, TG, HDL, LDL of blood serum were done in different groups. 
Results are shown in graph form. Studying changes in serum concentrations of cholecystokinin, TC, TG, HDL, LDL in different groups shows that the control groups did not show significant differences with each other. (Table 1 and Figures 1 to 5).

The average concentration of cholecystokinin hormone in the group receiving the extract of caraway 60 and $90 \mathrm{mg} / \mathrm{kg}$ compared to the control group showed a significant increase in the level of $\mathrm{P} \leq 0.05$ (Table 1 and Figure 1).

The average concentration of triglycerides, total cholesterol, and LDL in the groups receiving caraway 60 and $90 \mathrm{mg} / \mathrm{kg}$ showed a significant decrease compared to the control group (Table 1 and Figure 2, 3 and 5).

In comparison of the groups receiving the caraway extract with each other, it was found that $90 \mathrm{mg} / \mathrm{kg}$ concentration compared to the other concentrations has a greater effect in reducing serum levels of total cholesterol, triglycerides, and LDL (Figures 2, 3, and 5).

Mean serum concentration of HDL in the groups receiving caraway extract 60 and $90 \mathrm{mg} / \mathrm{kg}$ compared to control showed non-significant increase in the level P $₫$ 0.05 (Table 1 and Figure 4).

Table 1. Comparison of means of different groups about the concentration of the parameters investigated

\begin{tabular}{|c|c|c|c|c|c|}
\hline $\begin{array}{l}\text { PARAMETERS } \\
\text { GROUP }\end{array}$ & $\operatorname{CCK}(n g / l)$ & TG (mg/dl) & TC (mg/dl) & HDL (mg/dl) & LDL (mg/dl) \\
\hline $\begin{array}{l}\text { First } \\
\text { control }\end{array}$ & $1001 \pm 31.89 \mathbf{A}$ & $\begin{array}{l}149.62 \pm 4.23 \\
\text { C }\end{array}$ & $67.62 \pm 1.62 \mathbf{B}$ & $46.12 \pm 1.25 \mathrm{~A}$ & $26.87 \pm 0.83 \mathbf{A}$ \\
\hline Last day control & $988.2 \pm 28.88 \mathrm{~A}$ & $\begin{array}{l}146.02 \pm 6.54 \\
C\end{array}$ & $68.37 \pm 2.85 \mathbf{B}$ & $45.62 \pm 2.56 \mathrm{~A}$ & $27.01 \pm 0.80 \mathbf{A}$ \\
\hline $\begin{array}{l}\text { carum carvi } 60 \\
\mathrm{mg} / \mathrm{kg}\end{array}$ & $1106.23 \pm 44.16 \mathbf{B}$ & $\begin{array}{l}129.87 \pm 2.21 \\
\text { B }\end{array}$ & $55.87 \pm 3.39 \mathrm{~A}$ & $49.87 \pm 1.96 \mathbf{A}$ & $21.12 \pm 0.87 \mathbf{B}$ \\
\hline $\begin{array}{l}\text { carum carvi } 90 \\
\mathrm{mg} / \mathrm{kg}\end{array}$ & $1113.87 \pm 25.42 \mathbf{B}$ & $\begin{array}{l}108.25 \pm 4.07 \\
\mathbf{A}\end{array}$ & $50.62 \pm 1.26 \mathrm{~A}$ & $50.88 \pm 2.04 \mathrm{~A}$ & $18.75 \pm 0.92 \mathbf{B}$ \\
\hline
\end{tabular}

$\mathbf{C C K}=$ Cholecystokinin, $\mathbf{T G}=$ Triglyceride, $\mathbf{T C}=$ Total Cholesterol, $\mathbf{H D L}=$ High Density lipoprotein, $\mathbf{L D L}=$ low Density lipoprotein

-The means are presented in the form of Mean \pm SEM 
$* \mathrm{P}<0.05$ is considered statistically significant

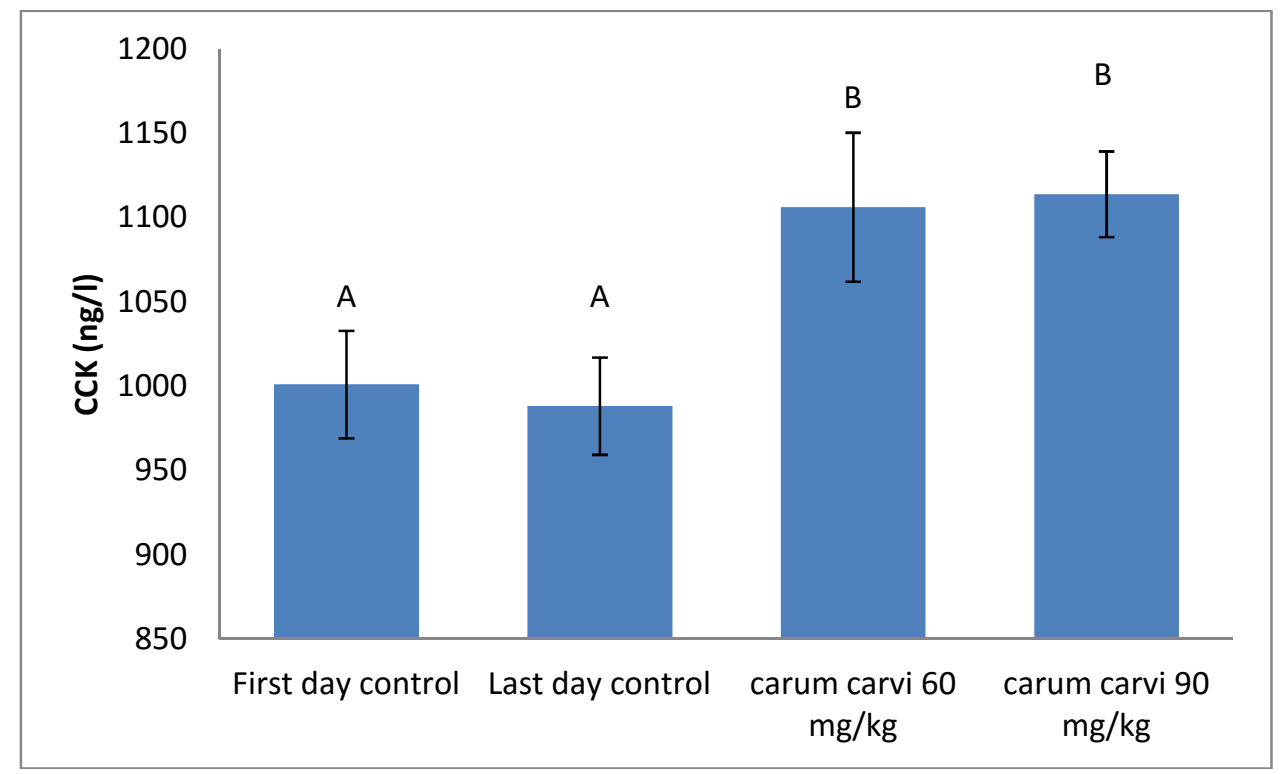

Fig.1. Mean serum level of cholecystokinin hormone in the groups studied Means in each column having at least one common letter, based on Duncan test, have no significant difference

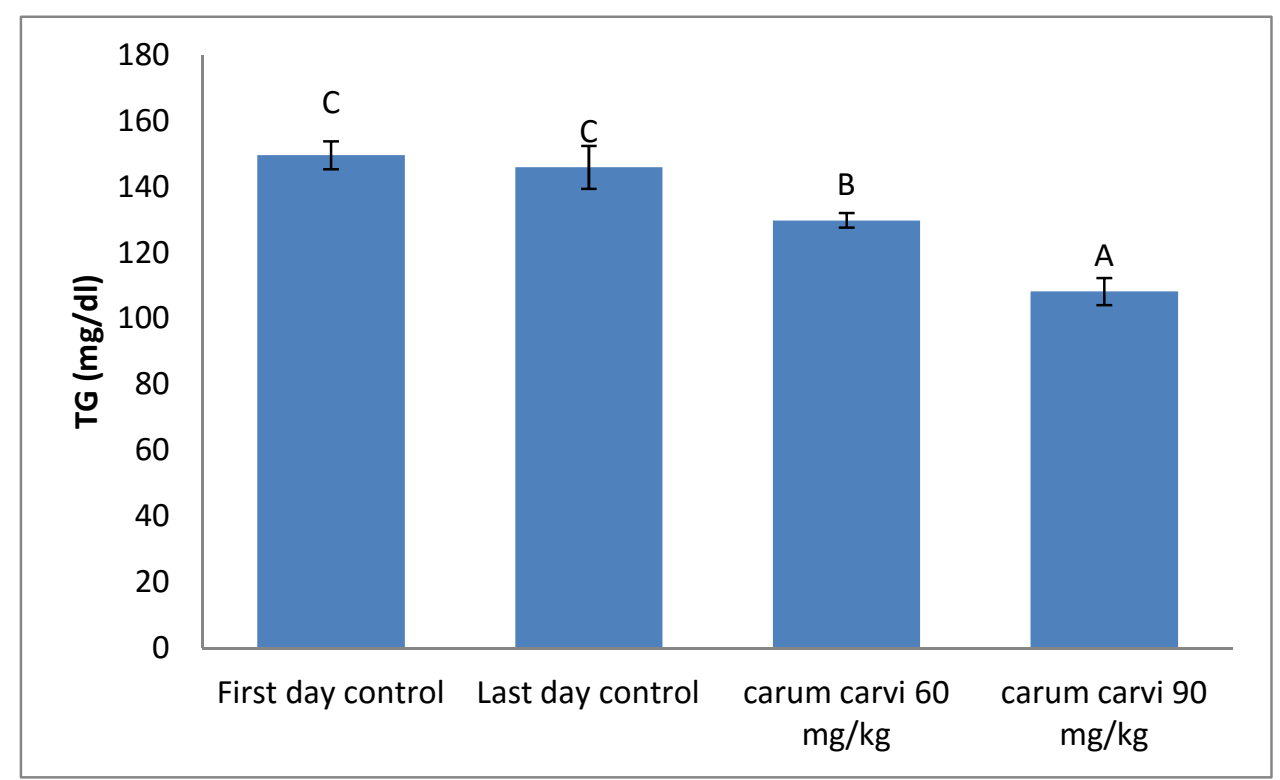

Fig.2. Mean serum level of TG in the groups studied

Means in each column having at least one common letter, based on Duncan test, have no significant difference 


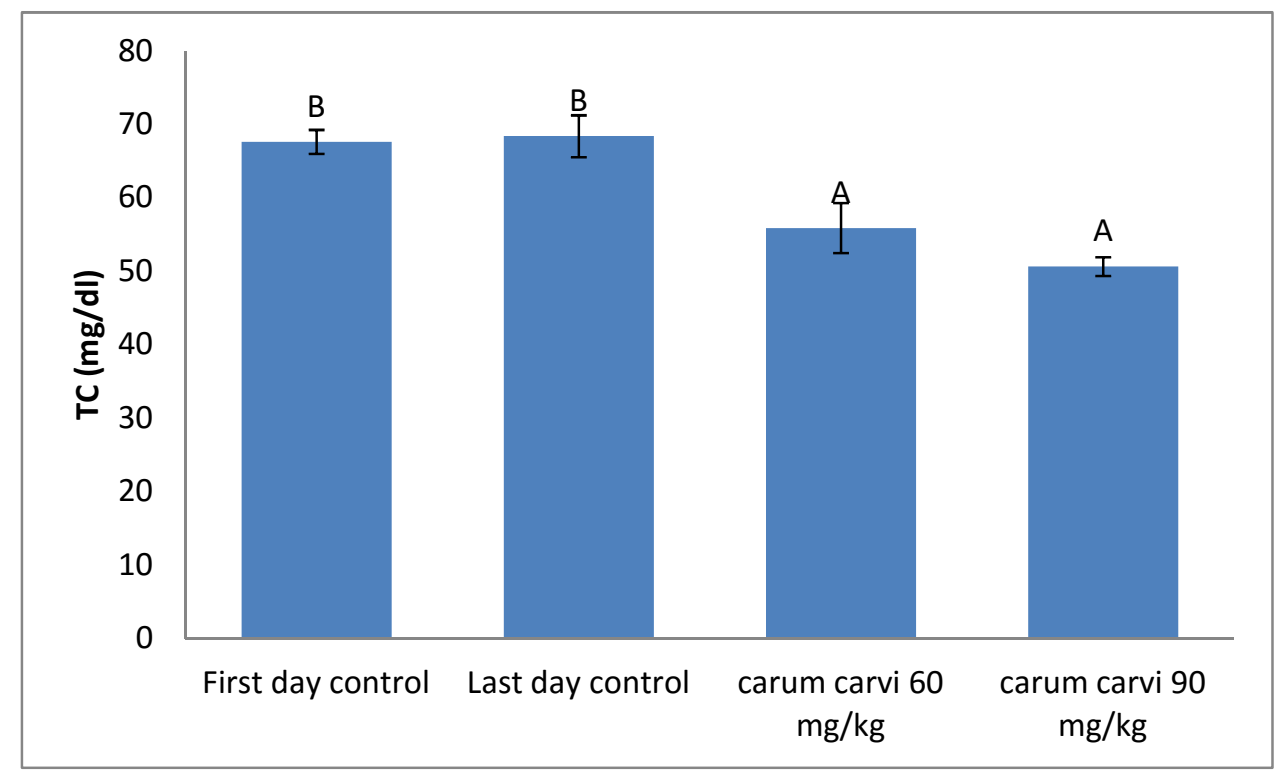

Fig.3. Mean serum level of TC in the groups studied

Means in each column having at least one common letter, based on Duncan test, have no significant difference

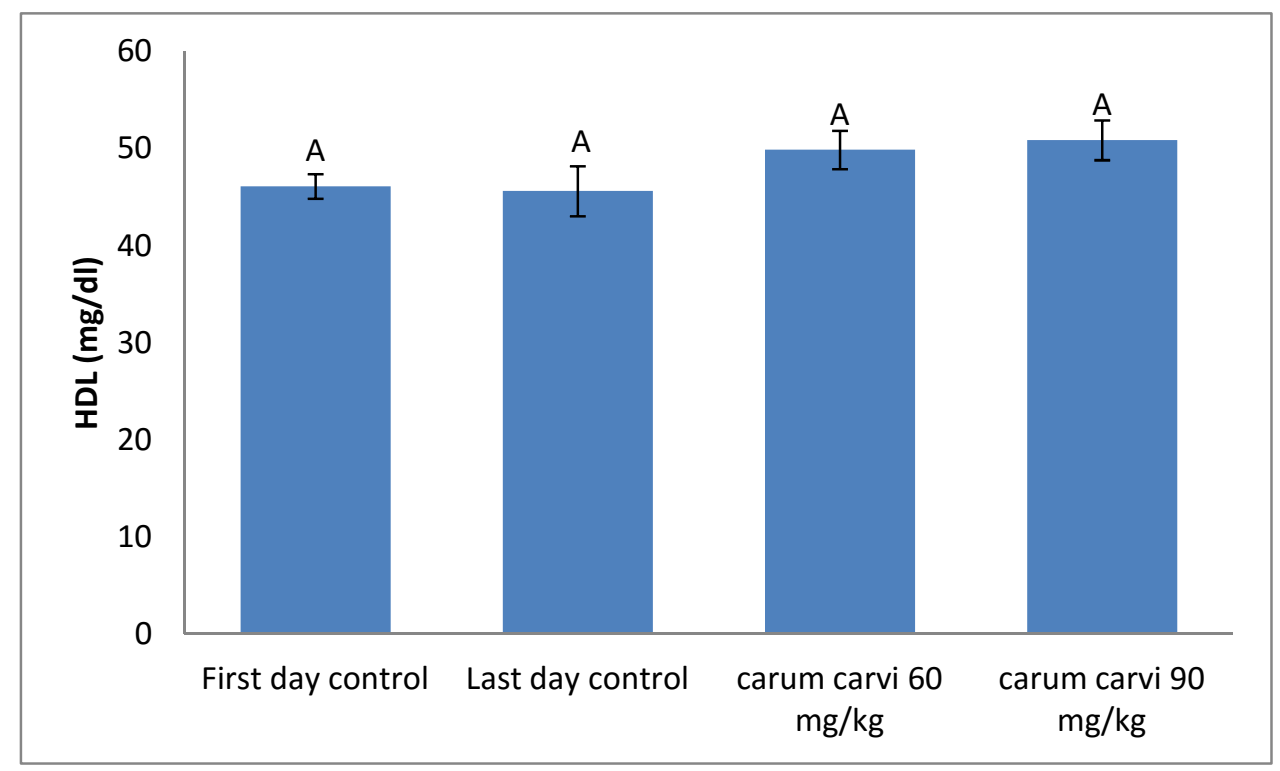

Fig.4. Mean serum level of HDL in the groups studied

Means in each column having at least one common letter, based on Duncan test, have no significant difference 


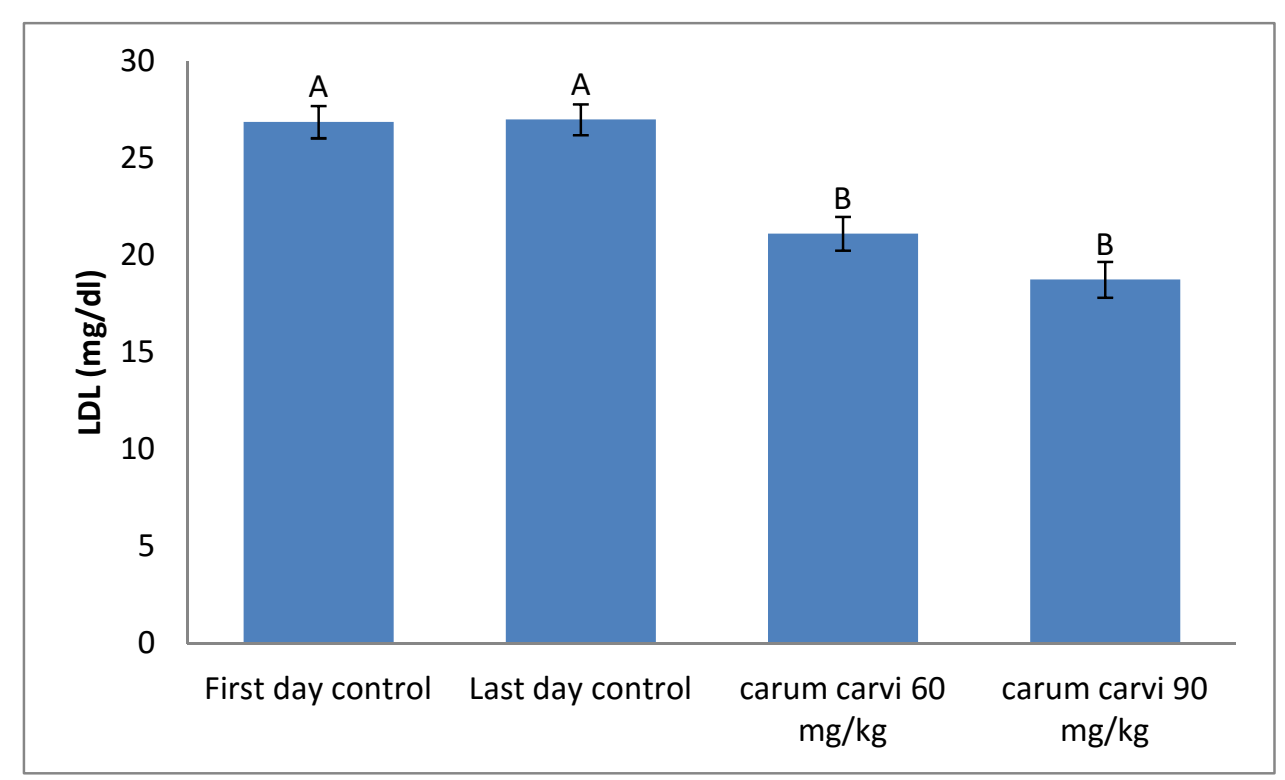

Fig.5. Mean serum level of LDL in the groups studied

Means in each column having at least one common letter, based on Duncan test, have no significant difference

\section{DISCUSSION AND CONCLUSION}

Based on the result of this study, aqueous extract of caraway increases serum concentrations of cholecystokinin hormone in male Wistar rats. The results also show that the dose-dependent consumption of caraway extract decreased LDL, TC, and TG. The results obtained in this study are consistent with the results of other studies on the effect of caraway extract on lipid profile, so that caraway extract decreases TG and cholesterol in normal and diabetic rats (15). Based on the findings of previous studies, anti-lipid features of caraway may be related to anti-bacterial, antioxidant, and anti-inflammatory features of the plant (16), which is created due to the presence of phenolic compounds including carvone, flavonoids, and Unsaturated Fatty Acid. These compounds are among the most important constituents of caraway extracts (17).

The presence of antimicrobial compounds stops combining of pathogenic microorganisms, leads to the growth and reproduction of beneficial intestinal bacteria, and thereby enhances the process of digestion of fat metabolism $(18,19)$. On the other hand, intestinal micro-flora (Gut Microflora) could lead to the expression of genes involved in lipid metabolism (20-22). There is also the theory that anti-inflammatory reactions cause fat reduction, so caraway by having this feature plays an important role in reducing body fat (23). 
Some compounds of caraway with their antioxidant features reduce fat. Among these substances are phenolic compounds that inhibit lipid peroxidation and increase apoptosis of pre-adipocytes (24). UFA that is of caraway compounds can cause oxidation of fatty acid and lipolysis of fat $(25,26)$.

Finally, in recent studies, it has been found that the aqueous extract of caraway by reducing intestinal absorption of lipid by binding to bile acids reduces fat (27).

According to the research, caraway increases T3 and T4 hormones and reduces TSH (28), which increases the metabolism of fat.

Specifically, about the reduction of cholesterol biosynthesis, one can say that black caraway reduces the activity of 3-hyrdoxy-3-methyl-glutaryl coenzyme A reductase (HMG-coA reductase) that plays a key role in the biosynthesis of cholesterol (29). It also reduces nicotinamide adenine dinucleotide phosphate (NADPH) required for the synthesis of fatty acids and cholesterol (30).

It is specified that glycemic control is one of the major determinants of VLDL plasma and TG, so strong decrease of fat that is of the properties of caraway can be attributed to its hypoglycaemic strength (31).

This study is conducted aimed to investigate the effect of aqueous extract of caraway on cholecystokinin hormone and at the results, a significant increase in this hormone was observed that giving that the most powerful triggers of the secretion of CCK are the products of fat breakdown, such as fatty acids obtained from the breakdown of triglycerides (32), this result is justified.

In the process of regulating the secretion of cholecystokinin, it is said that leptin increases the release of CCK from STC-1 cells (33). Given that in the results of previous studies, extract of caraway causes increase in the secretion of leptin hormone of the stomach cells, increasing in the secretion of cholecystokinin hormones can be considered to be caused by increase in secretion of leptin (34). 


\section{OVERALL CONCLUSIONS}

Due to antioxidant effects, caraway enhances cholecystokinin hormone secretion and reduction of triglyceride, total cholesterol, and LDL in the rats. However, to determine the exact mechanism of the effect of caraway extract, there is need for more complementary research.

\section{ACKNOWLEDGMENTS}

The present article has Jums.REC.1393.108 code of Jahrom University of Medical Sciences and Research Ethics Committee and some of the results are related to medical thesis of Ms. Yasaman Rooeintan (M.D. Degree). Hereby, the authors thank Vice Chancellor for Research and Technology Laboratory of Animal House in Jahrom University of Medical Sciences University who had the cooperation necessary in the present research.

\section{Conflict of interest}

The authors declared no conflicts of interest.

\section{REFERENCES}

1. James B, Wyngaarden. Cecil text book of Medicine. Ed, WB Saunders Company, 1996,1164-69

2. Wen-Ling Tsai, Chun-Yuh Yang, Sheng-Fung Lin and Fu-Min Fang, Impact of Obesity on Medical Problems and Quality of Life in Taiwan; American Journal of Epidemiology; 2004;160(6):557-565.

3. Mirzazadeh,A:" The Prevalence of Obesity in Iran in Recent Decade; a Systematic Review and Meta-Analysis Study”. Iranian J Publ Health:2009,3,7.

4. Pinel J(2007).Physiological psychology, fourth edition.culombia,406

5. Kianbakht s. A review of medicinal plants used in the treatment of obesity and overweight.medicinal plants.2010.4(9);36.

6. Zargari A. Medicinal plants. Tehran: Tehran University Publication. 2007; pp: 64-6. [Persian] 
7. Fatemi F,Alameh A,Khalfi H,Rezaei M,Sihoon M. The effect of alcoholic extract of Carum Carvi and oxidative stress parameters in rats with acute lung inflammation before and after gamma irradiation. Scientific-Research of Medicinal and Aromatic Plants.2009,442,4

8. Zargari A. [Medicinal plants]. Tehran: Tehran University Publication. 2007; pp: 64-6. [Persian]

9. Sekine T, Sugano M, Majid A, Fujii Y. Antifungal effects of volatile compounds from black zira (Bunium persicum) and other spices and herbs. J Chem Ecol. 2007 Nov;33(11):2123-32.

10. Oroojalian F, Kasra-Kermanshahi R, Azizi M, Bassami MR.Phytochemical composition of the essential oils from three Apiaceae species and their antibacterial effects on food-borne pathogens. Food Chemistry. 2010; 120(3): 765-70.

11. Jalilzadeh-Amin G, Maham M, Dalir-Naghadeh B, Kheiri F.Effects of Bunium persicum (Boiss) essential oil on the contractile responses of smooth muscle (An in vitro study). Vet Res Forum.2011; 2(2): 87-96.

12.Hajhashemi V, Sajjadi SE, Zomorodkia M. Antinociceptive and anti-inflammatory activities of Bunium persicum essential oil,hydroalcoholic and polyphenolic extracts in animal models. Pharm Biol. 2011 Feb;49(2):146-51.

13. Mandegary A, Arab-Nozari M, Ramiar H, Sharififar F. Anticonvulsant activity of the essential oil and methanolic extract of Bunium persicum (Boiss). B. Fedtsch. J Ethnopharmacol. 2012 Mar;140(2):447-51.

14. Saghir MR, Sadiq S, Nayak S and Tahir MU. Hypolipidemic effect of aqueous extract of Carum carvi(black Zeera) seeds in diet induced hyperlipidemic rats. Pak J Sci. 2012 Apr; 25(2):333-7.

15. Lemhadri A ,Hajji L, Michel J-B, Eddouks M. Cholesterol and triglycerides lowering activities of caraway fruits in normal and streptozotocin diabetic rats(2006).Journal of Ethnopharmacology ,106,321-326.

16. Saghir MR, Sadiq S, Nayak S and Tahir MU. Hypolipidemic effect of aqueous extract of Carum carvi(black Zeera) seeds in diet induced hyperlipidemic rats. Pak J Sci. 2012 Apr; 25(2):333-7. 
17. Fang R,Jiang $\mathrm{CH}$,Wang $\mathrm{XY}$,et al.Insecticidal activity of essential oil of carum carvi fruits from Chinaand its main components against two grain storage insects.Molecules 2010;15(12):9391-9402.doi:10.3390/molecules 15129391

18. Iacobellis NS, Lo Cantore P, Capasso F, Senatore F. Antibacterialactivity of Cuminum cyminum L. and Carum carvi L. essential oils.J Agric Food Chem 2005;53(1):57e61.

19. Hawrelak JA, Cattley T, Myers SP. Essential oils in the treatment of intestinal dysbiosis: a preliminary in vitro study. Altern MedRev 2009;14(4):380e4.

20. Can Baser K. Biological and pharmacological activities of carvacrol and carvacrol bearing essential oils. Curr Pharm Des 2008;14(29):3106e19.

21. Michiels J, Missotten J, Fremaut D, DeSmet S, Dierick N. In vitro dose-response of carvacrol, thymol, eugenol and trans-cinnamaldehyde and interaction of combinations for the antimicrobial activity against the pig gut flora. Livest Sci 2007;109(1e3):157e60. http://dx.doi.org/10.1016/j.livsci.2007.01.132.

22. Upreti RK, Kannan A, Pant A. Alterations in rat gut bacteria and intestinal epithelial cells following experimental exposure of antimicrobials. FEMS Immunol Med Microbiol 2008;54(1):60e9.

23. Wesseltoft-Rao N, Holven KB, Telle-Hansen VH, Narverud I, Iversen PO, Hjermstad MJ, et al. Measurements of body fat is associated with markers of inflammation, insulin resistance and lipid levels in both overweight and in lean, healthy subjects. ESPEN J 2012;7(6):e234e40. http://dx.doi.org/10.1016/j.clnme.2012.10.002.

24. Samojlik I, Lakic N, Mimica-Dukic N, Dakovic-Svajcer K, Bozin B. Antioxidant and hepatoprotective potential of essential oils of coriander (Coriandrum sativum L.) and caraway(Carum carvi L.) (Apiaceae). J Agric Food Chem 2010;58(15):8848e53. http://dx.doi.org/10.1021/jf101645n.

25. Iyer A, Fairlie DP, Prins JB, Hammock BD, Brown L. Inflammatory lipid mediators in adipocyte function and obesity. Nat Rev Endocrinol 2010;6(2):71e82. http://dx.doi.org/10.1038/nrendo.2009.264. 
26. Kalupahana NS, Claycombe KJ, Moustaid-Moussa N. (n-3) fatty acids alleviate adipose tissue inflammation and insulin resistance: mechanistic insights. Adv Nutr 2011;2(4):304e16. http://dx.doi.org/10.3945/an.111.000505.

27. Lemhadri A, Hajji L, Michel JB, Eddouks M. Cholesterol and triglycerides lowering activities of caraway fruits in normal and streptozotocin diabetic rats. J Ethnopharmacol 2006;106(3):321e6. http://dx.doi.org/10.1016/j.jep.2006.01.033.

28. Dehghani F, Panjehshahin MR, Vojdani Z. Effect of hydroalcoholic extract of caraway on thyroid gland structure and hormones in female rat. Iran J Vet Res 2010;11(4):337e41.

29. Kedar, P., Chakrabarti, C.H., 1982. Effects of bittergourd (Momordica charantia)seed and glibenclamide in streptozotocin induced diabetes mellitus.Indian Journal of Experimental Biology 20, 232-235.

30. Chi, M.S., 1982. Effects of garlic products on lipids metabolism in cholesterol fed rats. Proceeding of Society of Experimental Biology and Medicine 171, 174-178.

31. Eddouks, M., Lemhadri, A., Michel, J.-B., 2004. Caraway and caper: potential anti hyperglycaemic plants in diabetic rats. Journal of Ethnopharmacology 94, 143-148.

32.Green GM.Feedback inhibition of CCK secretion by bile acids and pancreatic proteases.Ann NY Acad Sci 1994;713;167-79.

33. Akram Ahangarpour, Ashraf Amir Zargar, Fatemeh Davoodi etal.The effects of aqueous and hydro alcoholic extract of Carum carvi on insulin resistance and metabolic. 19th National \& 7 th International Congress of Biology, Tabriz,Iran, 2016. http://19thbc2016.tabrizu.ac.ir/

34. Guilmeau(s),Buyse M, Tsocas A, Laigneau J, and Bado A. Duodenal Leptin Stimulates Cholecystokinin Secretion. Diabetes 52:1664-1672.

\section{How to cite this article:}

Pourahmadi M, Jahromi H K and Rooeintan Y. The effect of aqueous extract of caraway seed (carum carvi) on cholecystokinin hormone in male rat. J. Fundam. Appl. Sci., 2016, 8(4S), 2023-2035. 